\title{
Application of a process improvement method for improving usability
}

Stanisław Plebanek

Lean Enterprise Institute Polska

ul. Muchoborska 18, 54-424

Wrocław, Poland

Email:

stanislaw.plebanek@lean.org.pl

\begin{abstract}
The paper investigates whether the user-interface interaction can be shortened with the use of process improvement methods. Similarities between office or factory work and interacting with a user interface have been noticed. Based on that a relevant process improvement method has been selected and applied to analyze different cases of interactions between a user and an interface. This analysis has shown that process improvement methods enable identification of interface elements to be modified in order to shorten the user-interface interaction. Additionally, the method has been found to be a way for facilitating identification of ideas for new services.
\end{abstract}

\section{INTRODUCTION}

$\mathrm{A}$ $\mathrm{S}$ users of devices, we deal with User Interfaces (UI) every day: switching the TV channels, setting the temperature in a car or buying things through vending machines. Some of these interactions with interfaces are more memorable than others. Especially when the interfaces are so poorly designed that while using them one can easily notice the waste of time caused by steps or screens displayed at the digital interface which are irrelevant for the current customer. This experience is even worse when one interacts with a poorly designed interface when being under time pressure. As a result of using an interface with a poor usability the users get frustrated, can make errors [1] and thus the interaction takes more time than it could.

On the other hand, there is a well-developed body of knowledge that deals with process improvement. Organizations like factories, banks, design offices, hospitals, accounting and others strive to improve their processes. They use standardized work [2], SMED [3], TWI-JM [4], MTM [5] and other methods to improve safety, increase productivity or improve process quality.

Being a user who interacts with UI's and being a bank or factory employee - the similarities exist. In both cases, the person executes some kind of a process. According to a definition process is "a series of actions or steps taken in order to achieve a particular end". Therefore selecting

The research leading to these results has received funding from the European Union Seventh Framework Programme (FP7/2007- 2013) under grant agreement $n^{\circ} 609143$. The paper reflects only the author's views and that the Union is not liable for any use that may be made of the information contained therein. certain icons on the screen or any other user-interface interaction which leads towards achieving the desired goal is also a process. And if it is a process, it leads to a question: can the user-interface interaction be improved with the use of process improvement tools? Which process improvement tools should be applied in order to improve the userinterface interaction?

\section{II.PROCESS IMPROVEMENT}

\section{A. Methods for improving user-interface interaction}

Improving user interactions is part of improving the usability of an interface. For that purpose several methods have been already developed including: customer journey map [6], service blueprinting [7] or the GOMS model [8]. Additionally there has been work conducted on applying Lean Management principles to improve User Experience [9]. Out of the above mentioned methods only the last one is somehow related to the process improvement tools. However it focuses on how to manage the product or service design process and does not go into detail on how to identify improvement potential at the level of interactions between the user and the interface of a device.

\section{B. Training Within Industry}

Out of identified process improvement methods one is relevant to improve the work with the machine interface: the Training Within Industry - Job Methods [10] which is part of the original Training Within Industry (TWI) program.

The whole TWI program was created during II World War by the United States Department of War. It was developed for the American industry which started running short of personnel because of a large number of men in productive age fighting in the war. Industrial companies had to start to employ women as welders, riveters or milling machine operators even though they were not skilled for those positions. The program was dedicated to mid- and low-level managers. Its aim was to quickly develop new, talented production employees in order to achieve increase in productivity and quality [11] 
TWI program focuses on developing Five Needs of supervisor: knowledge of work, knowledge of responsibility, skill in instructing, skill in improving methods, and skill in leading. These needs have been taught in relevant parts of the training: Job Instruction, Job Methods, Job Relations, Union Job Relations and Program Development [13]. Training Within Industry - Job Methods (TWI-JM) is the element of the program that helps to develop the supervisor's skill in improving work methods. It is an analytical tool that helps to understand the current state of a process and give insights how it can be improved in terms of productivity, quality [11], and also safety, ergonomics and comfort. The TWI-JM method consists of 4 steps. Step number 1. "Break down the job" helps to answer the questions: How the activity is performed? What are the subsequent steps? and is concluded with a list of steps. Step number 2. "Question every detail" answers why the activity is performed that way. In this step 5W1H questions (Why is it necessary? What is its purpose? Where should it be done? When should it be done? Who is best qualified to do it? How is the 'best way' to do it?) are being used. Step 3. "Develop the new method" helps to understand if there are other ways the work can be performed in a better way in terms of effort, quality etc. There are four types of improvements possible: elimination of unnecessary details, combining details, rearranging them for better sequence and simplifying details. This step concludes with a proposed new method written down to the level of subsequent steps. Step 4. "Apply the new method" helps to get final approval of all employees concerned including other operators and a manager. It concludes with the method being in use. [14]

\section{TWI-JM FOR IMPROVING USER-INTERFACE INTERACTION}

TWI-JM has been selected to be a methodological base for improving user-interface interaction. In order to meet this purpose the method has been adapted and is presented in Fig. 1. Improving a user-interface interaction bases always on existing products or services. Therefore the method should be applied for a specific product or service. It cannot be applied for a product idea or concept nor for a generic product. Like the first principle of Lean Management [15] the developed method focuses on the customer - it does not enhance improving the interaction from other perspective than the users' one.

The method starts with selecting a process that will be analyzed and improved. The user may interact with an interface of one device for multiple reasons - the method requires selecting one of those reasons and a process associated with it. Processes differ from each other and can be analyzed one at a time. Changes in the interface may positively impact one process, but they may negatively influence the other ones. Therefore it is important to start the analysis from those processes which are most important to the specific users' group. Selection of those processes should be done together with the users. The most important processes may be ones that take the most of the time a user interacts with the product. These may also be those processes that strongly influence the quality of the work being done with the use of the product (e.g. setting processing parameters at a machine). These may also be activities that most significantly prevent the product from being used the way the user would like to use it (e.g. activities preventing a manufacturing machine from producing, like changeovers or maintenance). The most important processes may also be ones that don't take a lot of time but are done at the time where there is an accumulation of tasks (e.g. preparing the discrepancies report at the end of month by an accountant).

After selection the process needs to be deeply understood. It is done by observations at the place where it is conducted and by breaking it down into steps. In this step filming the process may be of help. It enables people using the method to repeat watching certain steps of the process in order to better understand what has been done and reflect on it.

After breaking the process down the way the process is conducted needs to be questioned. $5 \mathrm{~W} 1 \mathrm{H}$ questions are being used at this step. They help to understand if there are other ways the interface could be organized in order for the interaction to be shorter or to provide better quality. It is important to ask these questions in the order provided (Why is it necessary? What is its purpose? Where should it be done? When should it be done? Who is best qualified to do it? How is the 'best way' to do it?). That is because if one questions the aim of the step and has the idea to eliminate it there is no need to think how to conduct that step in an improved way. The results of this detailed analysis are insights on what prevents the product from better meeting the user needs in terms of efficiency, ergonomics or more generally in terms of usability.

The last stage of the method is the definition and selection of improvements. The steps which have been questioned during $5 \mathrm{~W} 1 \mathrm{H}$ analysis are being brought to attention. For each of them brainstorming should be organized in order to generate improvement ideas. In order to decide the implementation scope and order each of the ideas should be assessed whether it's easy or difficult to implement and whether it is perceived by the user as of high or low effect. After deciding which improvements should be implemented (first the easy ones with high effect) the last part of the method is to put the ideas in life and apply the new way the interface is interacting with the user.

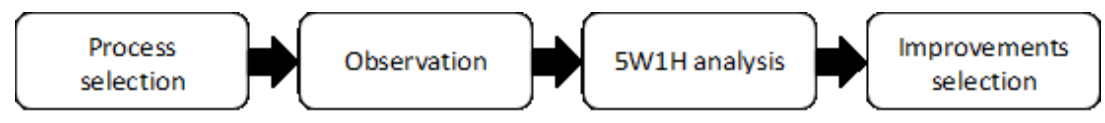

Fig. 1 Method for improving user-interface interaction for a certain product/service 


\section{RESULTS}

The above described method has been applied in various scenarios: from buying a train ticket via a vending machine, through a changeover of an electric-discharge machine to entering address in a car navigation system. These cases have been selected because a relatively significant portion of user time is spent on active interaction with the user interface. In these cases the user needs to take a decision, press a button, set a value etc. in contradiction to waiting for the device to process an information or conduct a process without or with a relatively small amount of user activity. The method provides best results for those types of userinterface interactions. Below buying petrol at a self-service petrol station has been described in detail in order to describe the method in practice. It has been selected as it is not a complex nor a long process and therefore it is good to

TABLE I.

JOB BREAKDOWN SHEET FOR PAYMENT FOR FUEL AT A SELF-SERVICE PETROL STATION EMILA.

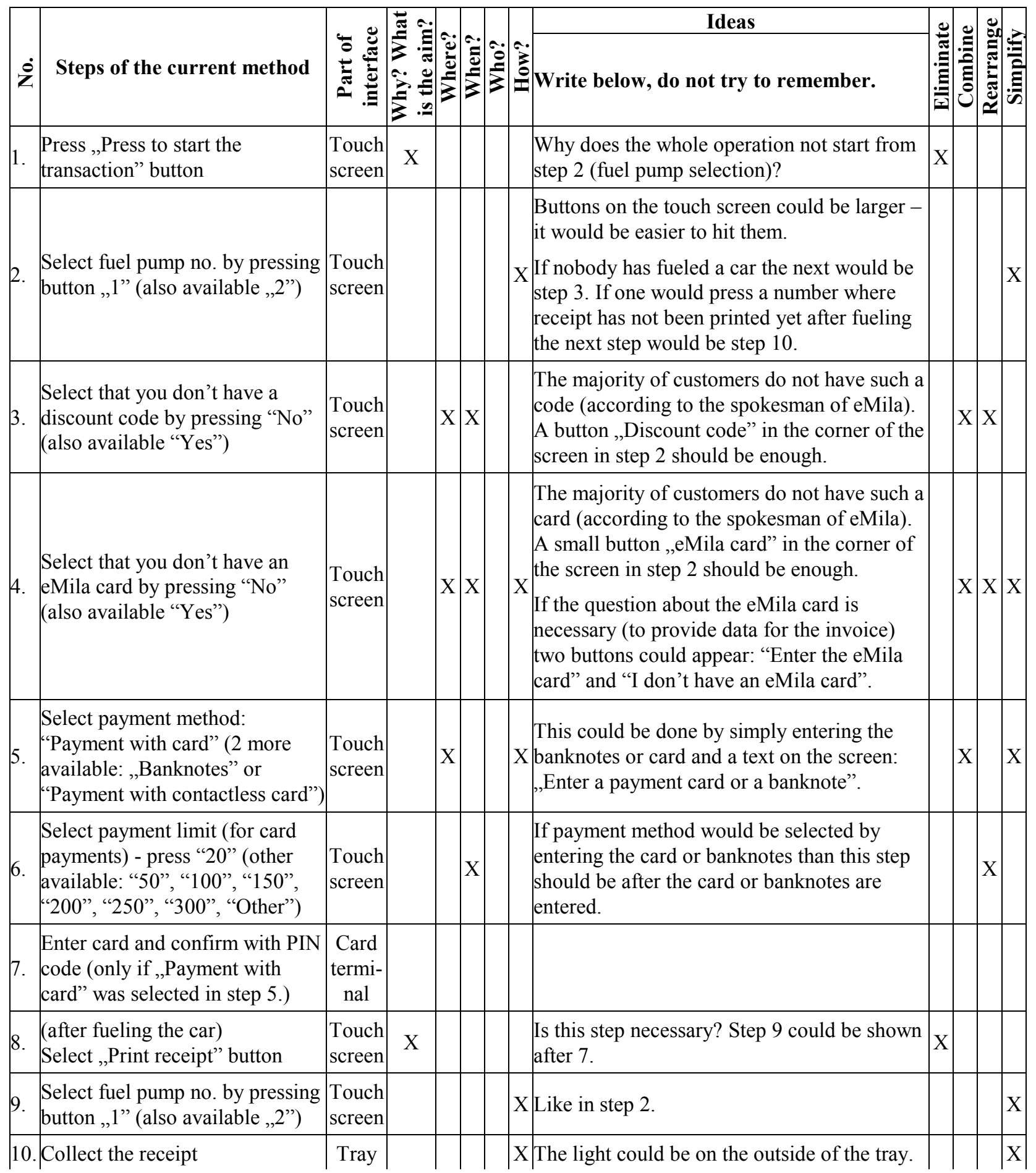


explain the method. It is also a good example of a case where the method could be applied because a vast majority of users of self-service petrol stations have one goal - fuel up their cars. So there is one main goal the interface should enable to obtain. And for such cases the method suits best.

\section{A. Buying petrol at a self-service petrol station}

Self-service petrol stations are not the most common ones. Petrol companies prefer to have a store at the station so they can sell a variety of items and not only fuel. However there is a group of customers who do not buy additional items while at the petrol station and who do not like to waste their time staying in a queue when other customers who are before them order hot beverages or buy other items. Self-service petrol stations are for them. However as this group of people values their time it is important for the station to provide services as seamlessly as possible and without any unnecessary activities required from the user.

The process of buying the fuel at such a petrol station has been analyzed from a perspective of a person who uses the station from time to time. The purchase was done with a card and for a limited, predefined amount of money. The study does not cover the process of fueling up the car. The analysis has been presented in Table I. After purchasing the fuel and filming it all the steps have been described one by one ("Steps of the current method") and described whether this step was done at the touch screen, card terminal or at the tray ("Part of interface"). The next step of the method is to ask $5 \mathrm{~W} 1 \mathrm{H}$ questions and provide a vast number of improvement ideas basing on answers to those questions. In columns "Why? What is the aim?", "Where?", "When?", "Who?" and "How?" in a case where there is an idea how to organize a step in a better way according to these questions an " $\mathrm{X}$ " is placed to mark in which way the status quo is being challenged. In the column "Ideas" all the improvement ideas related to previously marked " $X$ " have been noted. And finally ("Eliminate"-"Simplify") out of all the ideas the ones that are relevant, have a business potential and are feasible have been selected for implementation and an " $\mathrm{X}$ " has been placed in the relevant row and column.

In this single case the time of buying fuel (without fueling up the car) could be shortened from around 63 seconds down to around 47 seconds which equals to $25 \%$ time reduction. This data is based on a video analysis. This can mean more satisfied customers due to shorter service time but also increased revenue in the case of queues to pumps due to shorter pump occupation by a single customer.

\section{V.DISCUSSION}

The research has shown that a process improvement method may be applied to improve user-interface interaction. The TWI-JM has been adapted and used to identify areas where the time of this interaction can be shortened. This way the overall usability of the analyzed product or a service may be improved. Based on different cases out of which each was conducted only by one user it has been observed that the interaction time could be shortened from $20 \%$ to $74 \%$. Assessing more accurate values would require analyzing a larger sample of similar cases.

The research described in this article has been limited only to one method. No deep assessment of the method against predefined criteria has been done. The increasing role of usability in the overall perception of products and services implies further research. Work on comparing the method with the other methods that enable improving the userinterface interaction is required in order to develop a framework which would help to select tools in accordance to problems being solved.

The adapted method is applicable only for existing processes, or at least for those that can be observed in real settings and broken down into steps. Another disadvantage of the method is that it enables to analyze only one process at a time. The adapted TWI-JM enables benchmarking of competitive products or services however one needs to analyze them in a similar way and compare step by step.

\section{REFERENCES}

[1] R. M. Ratwani, R. J. Fairbanks, A. Z. Hettinger, and N. C. Benda, "Electronic health record usability: analysis of the usercentered design processes of eleven electronic health record vendors," J. Am. Med. Informatics Assoc., vol. 22, no. 6, pp. 1179-1182, 2015. doi: 10.1093/jamia/ocv050

[2] P. Rewers, M. Mandziuk, and J. Trojanowska, “Applications Use Standardized Work Purpose of Increase the Production Capacity-a Case Study," Res. Logist. Prod., vol. 5, 2015.

[3] A. Azizi and others, "Designing a future value stream mapping to reduce lead time using SMED-A case study," Procedia Manuf., vol. 2, pp. 153-158, 2015. doi: 10.1016/j.promfg.2015.07.027

[4] K. Misiurek and B. Misiurek, "Methodology of improving occupational safety in the construction industry on the basis of the TWI program," Saf. Sci., vol. 92, pp. 225-231, 2017. doi: 10.1016/j.ssci.2016.10.017

[5] A. Marzano, K. Agyapong-Kodua, and S. Ratchev, "Virtual ergonomics and time optimization of a railway coach assembly line," Procedia CIRP, vol. 3, pp. 555-560, 2012. doi: 10.1016/j.procir.2012.07.095

[6] A. Richardson, "Using customer journey maps to improve customer experience," Harv. Bus. Rev., vol. 15, no. 1, 2010.

[7] M. J. Bitner, A. L. Ostrom, and F. N. Morgan, "Service blueprinting: A practical technique for service innovation," Calif. Manage. Rev., vol. 50, no. 3, pp. 66-94, 2008.

[8] B. E. John and D. E. Kieras, "Using GOMS for user interface design and evaluation: Which technique?," ACM Trans. Comput. Interact., vol. 3, no. 4, pp. 287-319, 1996.

[9] J. Gothelf and J. Seiden, Lean UX: Applying Lean Principles to Improve User Experience. O'Reilly Media, 2013.

[10] B. Misiurek, Standardized Work with TWI: Eliminating Human Errors in Production and Service Processes. CRC Press, 2016. P. Graupp and R. J. Wrona, "The TWI Workbook: Essential Skills for Supervisors." Taylor \& Francis, pp. xvii-xviii, 2006. J. Huntzinger, "The roots of lean," Train. Within Ind. Orig. Kaizen, Assoc. Manuf. Excell., vol. 18, no. 2, pp. 14-23, 2002. D. Dinero, "Training Within Industry: The Foundation of Lean." Taylor \& Francis, pp. 76-77, 2005.

[14] "Bureau of Training. Training Within Industry Service.," Job Methods: Sessions Outline and Reference Material. War Production Board, 1943.

[15] J. P. Womack and D. T. Jones, Lean Thinking: Banish Waste and Create Wealth in Your Corporation. Free Press, 2010. 